\title{
Justifications and Excuses in Epistemology
}

\author{
Penultimate Draft, Forthcoming in Nô̂s \\ Daniel Greco
}

\section{Introduction}

While epistemologists have long debated what it takes for beliefs to be justified, they've devoted much less collective attention to the question of what it takes for beliefs to be excused, and how excuses differ from justifications. ${ }^{1}$ This stands in stark contrast to the state of affairs in legal scholarship, where the contrast between justifications and excuses is a standard topic in introductory criminal law textbooks. ${ }^{2}$ My overarching goal in this paper is to extract some lessons from legal theory for epistemologists seeking to distinguish epistemic justifications from epistemic excuses. But my aim in looking to the law isn't just to take advantage of a larger literature. Epistemologists often worry that debates between proponents of different conceptions of epistemic justification threaten to be "merely verbal". 3 This sort of worry is particularly pressing for epistemologists who distinguish justifications from excuses. When all parties to a debate agree that a belief has something to be said in defense of it, but differ over whether that something

For helpful comments and discussion, thanks to Gideon Yaffe, and audiences at the University of Michigan, MIT, Oxford University, and Shandong University.

${ }^{1}$ Some notable recent exceptions include Boult (2017), Williamson (Forthcoming), Littlejohn (Forthcoming), Schechter (Forthcoming), and Madison (Forthcoming). 17).

${ }^{2}$ See, e.g., Robinson and Cahill (2012, Part IV), Allen (2015, Chapter 6), Dressler (2015, Chapter

${ }^{3}$ See Alston (1993, 2005), Greco (2015), Cohen (2016), and Ballantyne (2016). 


\section{Justifications and Excuses in Epistemology}

amounts to a justification or a mere excuse, it's natural to wonder just what turns on that distinction. And it's here that I intend to draw on legal scholarship; legal theorists not only debate the question of how to classify defenses as justifications or excuses, but also why it matters whether we classify a defense as a justification or an excuse - what further downstream legal consequences (ought to) turn on the classification. So my aim is to import from legal theory some tools for not only distinguishing justifications from excuses, but also vindicating that distinction as substantive.

My strategy in the paper will be as follows. First, I'll provide a brief overview of appeals to the justification/excuse distinction in epistemology. As a preview, the distinction has been discussed largely in the context of the internalism/externalism debate, and in recent years specifically in the context of debates about the "knowledge first" program in epistemology. Internalists point to cases in which a subject has a belief that seems justified, but which isn’t justified by externalist lights. Externalists respond that the belief is merely excused, not justified. Internalists say that the belief looks importantly different from other putative cases of merely excused beliefs. Externalists admit this, but hold that this merely shows that not all excuses are of the same kind. It's at this point that, absent some theory about what the justification/excuse distinction is for and so why it matters where we draw the boundary, the debate threatens to be deadlocked, and perhaps merely verbal. So I'll look to legal theory to extract some potential strategies for avoiding such a deadlock.

Unsurprisingly, legal theorists disagree about as much as epistemologists, so I won't try to import some settled, consensus doctrine. Rather, I'll identify choice points in legal theory for how to think about the function of the justification/excuse distinction, which will motivate corresponding ways of drawing the boundary between justifications and excuses, and will in turn correspond to analogous choice points in epistemology. I'll argue that by reference to certain legal principles, it's possible to motivate a traditional, nonfactive, broadly internalist conception of epistemic justification, on which false beliefs 
can be fully justified and need no excuse. By reference to other legal principles, it's possible to motivate a factive conception of epistemic justification, on which only true beliefs can be justified. But these principles will motivate a view where truth is all that's required for a belief to be justified - knowledge or reliability won't come into the picture, and so while the resulting picture is "externalist" in a sense, it fits awkwardly with typical externalist projects in epistemology.

\section{Justifications and Excuses in the Knowledge-First Pro- gram}

Consider the opening lines of the first chapter of Jonathan Sutton's Without Justification:

My view is that a subject's belief that $p$ is justified if and only if he knows that $p$ : justification is knowledge. (2007, p. 7)

Sutton's view faces an obvious objection, of which he is well aware: what about subjects who seem to be doing everything right, reasoning exactly as they ought, and who nevertheless form beliefs that don't amount to knowledge? To raise this objection against earlier forms of externalism — versions on which a justified belief must have been produced by a generally reliable process, but needn't be true - some outlandish cases were required. ${ }^{4}$ But against Sutton's view, it's enough to imagine a cognitively normal subject, call her Lara, in a largely normal environment - no demons or vats requiredconfronted by a piece of wax fruit, let's say a lemon. We may even suppose it's in a bowl of what is otherwise real fruit, and that Lara has already eaten a few genuine grapes. If Lara believes that she is in the presence of a lemon, then her belief - so the objection goes - is justified, despite not amounting to knowledge because false.

While Sutton himself doesn't use the language of "excuse" - though he does talk about these sorts of beliefs as "reasonable" and "blameless" - other knowledge firsters

\footnotetext{
${ }^{4}$ Most notably, the "New Evil Demon Problem", raised by Stewart Cohen (1984).
} 


\section{Justifications and Excuses in Epistemology}

do. Here's Timothy Williamson:

The brain in the vat's belief that it has hands is unjustified: it does not constitute knowledge, because it is false. What the brain in the vat has is a cast-iron excuse for the belief, not a justification. (Forthcoming)

The more general picture defended by Williamson is that the most fundamental norms for belief, action, assertion, and probably more, are properly characterized in terms of knowledge. One shouldn't believe, act on, or assert what one doesn't know. Justification is identified with successfully following these norms. So anyone who believes, acts on, or asserts what she does not know, fails to follow the relevant norm, and is at best excused. Moreover, while the details of the explanation vary depending on which knowledge-firster you ask, the existence of epistemic excuses is explained by their bearing some relation to knowledge. Perhaps a belief that doesn't amount to knowledge is excusable when the subject reasonably thinks she knows, ${ }^{5}$ or isn't in a position to know that she doesn't know, ${ }^{6}$ or is conducting her epistemic affairs as someone generally disposed to acquire knowledge in normal circumstances would. ${ }^{7}$

A relatively standard internalist response at this point is to object that, in some circumstances, forming a false belief is the right response to misleading evidence, and so requires no excuse. Some representative examples: ${ }^{8}$

So rather than demon world victims having merely excusable beliefs, we have reason to think that they have justified beliefs, since they are believing as they should, or as they ought, since their beliefs are praiseworthy, rather than the proper objects of criticism. (Madison, Forthcoming, p. 6)

Consider the case of an assertion in a Gettier-style case... or in the case of

\footnotetext{
${ }^{5}$ See DeRose (2002) and Hawthorne and Stanley (2008) for versions of this response. See Gerken (2011) for a critical response.

${ }^{6}$ See Srinivasan (2015).

${ }^{7}$ See Aarnio (2010), Williamson (Forthcoming).

${ }^{8}$ See also Pryor (2001, pp.117) for a earlier version of this reply.
} 


\section{Justifications and Excuses in Epistemology}

a justified false belief...According to the excuse response, Jones's assertion is improper but Jones is blameless for asserting it, since Jones has an excuse. The trouble is that it is not merely the case that Jones's assertion is blameless. Rather, Jones positively ought to make the assertion. When asked, he should say that it is 2:05 pm. If Jones does not say that it is 2:05 pm (and has no reason not to cooperate with his interlocutor), then he is criticizable for not asserting what he believes about the time. That Jones has an excuse for making the assertion, and is therefore blameless for so doing, does not explain this fact. (Schechter, Forthcoming, p.21)

The thought, as I interpret it, is that to label reasonable false beliefs as merely excused is to damn them with faint praise; excused beliefs include beliefs you form because you're a child, or insane, or drugged. To lump the beliefs of people like Lara-beliefs that are the product of impeccable reasoning - into such a category seems indiscriminating.

At this point, knowledge firsters have offered what I'll call the "Anna Karenina Response". Justified beliefs are all alike - they are all knowledge-but each merely excused belief is merely excused in its own way. That is, they'll agree that, despite all belonging to the category of "merely excused beliefs", there are important differences between false beliefs that are the product of proper cognitive functioning in an abnormal or uncooperative environment, and beliefs that are the product of blamelessly impaired cognitive functioning. But even granting that the former sorts of beliefs are in some interesting sense epistemically better or more praiseworthy than the latter, that doesn't mean they're justified. Williamson and Littlejohn both offer versions of this response:

Excuses are inexhaustibly various; one should not expect a neat taxonomy.

(Williamson, Forthcoming, fn. 7)

Excuses are a motley bunch. (Littlejohn, Forthcoming, p.10) ${ }^{9}$

\footnotetext{
${ }^{9}$ Littlejohn offering a characterization of Austin's position, to which he is sympathetic.
} 
At this point I want to step back and offer a very general characterization of what I take to be the common ground in the debate, with an eye towards motivating the worry that it's not entirely clear what substantive point is at issue. Both sides can agree that false beliefs are "somehow defective" (Williamson, Forthcoming, p.24), and that knowledge amounts to a kind of success; when the belief-forming process goes well, as it ideally should - in some sense of "should", at least-the belief thereby formed will amount to knowledge. Both sides also agree that in some cases of "unsuccessful" belief - i.e., belief that doesn't amount to knowledge - the failure to "succeed" does not reflect poorly in any sense on the believer, and in fact it would have reflected poorly on the believer if she had believed anything else; e.g., it would reflect poorly on Lara if she believed she was looking at a wax lemon, or even if she just suspended judgment on whether the lemon in front of her was wax or genuine. And both sides can also agree that some cases of unsuccessful belief reflect poorly in some sense on the believer, but in which we nevertheless wouldn't blame the believer in any thick sense of "blame". Consider the delusional beliefs that are sometimes the product of Parkinson's disease. As I understand the debate, all parties can agree that these beliefs are interestingly different, from an epistemic point of view, from Lara's. While blameless - I take it that nobody is blameworthy for developing Parkinson's disease, or for the ensuing symptoms - they are not the product of rational thought processes, the way Lara's belief is.

That's a lot of agreement-so what's the dispute? It can look as if all parties acknowledge the same set of theoretically significant distinctions among beliefs, and merely differ over how we should label those distinctions; knowledge firsters only honor successful beliefs with the label "justified", and while they recognize a theoretically significant distinction between beliefs like Lara's, and delusional beliefs, they class both sorts as merely excused. Their opponents also recognize a significant distinction between successful beliefs and Lara's - they needn't be knowledge eliminativists - but nevertheless apply the label "justified" to both. Following Chalmers (2011), I think a helpful way to 
frame the question of just what this difference could amount to is to ask what theoretical role we want the label "justified" to play — what further commitments do we take on by classifying a belief as justified, as opposed to merely excused?

It's here that I'll ultimately turn to legal theory for some inspiration, but before doing so, I'll briefly discuss one potential theoretical role for the label "justified" that I find already present in the epistemological literature. We might propose that the role of "justified" in epistemology is to mark the theoretically most fundamental distinction for the evaluation of beliefs - the distinction in terms of which all other epistemological distinctions are to be explained. ${ }^{10}$ In that case, if the knowledge firster is right that we can explain the significance of the various distinctions the internalist emphasizes - e.g., the distinction between beliefs like Lara's, and those of blamelessly deluded subjects - in terms of knowledge, then that's a point in her favor.

But, as a sociological matter at least, the idea that the role of "justified" in epistemology is to mark the most theoretically fundamental distinction for the evaluation of beliefs would be highly revisionary. In both epistemology and ethics, it's standard to distinguish values from norms, and to defend positions on which some fundamental value that is not itself a norm plays a key role in grounding norms. Rule utilitarians hold that the distinction between the value of pleasure and the disvalue of pain is the theoretically most fundamental distinction in ethics - all other ethical distinctions, such as the distinction between right and wrong action, are explained by appeal to that distinction. But they do not hold that the normative standard for action appeals directly to that value; this is what distinguishes them from act utilitarians. Rather, the relationship between the distinction between pleasure and pain on the one hand, and the distinction between right and wrong action on the other, is indirect-actions are justified insofar as they conform to the right rules, whose rightness is constituted by some relation they bear to

\footnotetext{
${ }^{10}$ This is suggested, I think, by some remarks of Williamson's where he defends the identification of justification with knowledge by pointing to the unifying power of an approach with knowledge norms at the foundation. See (Williamson, Forthcoming, p.24).
} 
the distinction between pleasure and pain. ${ }^{11}$ Traditional reliabilists hold a closely analogous position in epistemology. They hold that the distinction between the value of true belief and the disvalue of false belief is the most fundamental theoretical distinction in epistemology. Other distinctions, such as the distinction between justified and unjustified belief, are to be explained by appeal to that distinction. But again, they don't hold that the beliefs are justified just in case they manifest that fundamental value - they don't say that beliefs are justified just in case they are true. Rather, they hold that the relationship between the value of truth and the justification of belief is indirect; beliefs are justified when they are caused by the right processes, whose rightness is constituted by some relation they bear to the distinction between truth and falsity. ${ }^{12}$ The more recent "accuracy first" program in formal epistemology is similar; its proponents treat the value of accuracy in credence - closeness to the truth - as fundamental. But they don't say that credences are more justified to the extent that they are closer to the truth. Rather, the norms on credence they do discuss are defended indirectly; credences are justified just in case they conform to certain norms - probabilism, conditionalization, the principal principle - that are themselves vindicated by appeal to the value of accuracy. ${ }^{13}$

The point of all these examples is to show that it's routinely presupposed that the distinction between justified and unjustified actions, beliefs, and/or credences may not be theoretically fundamental, but instead explained by some more fundamental distinction, perhaps concerning some species of value. So if the knowledge firster defends the view that we should identify the knowledge/ignorance distinction with the distinction between justified and unjustified belief on the grounds that the distinction between knowledge and ignorance is the theoretically most fundamental distinction in epistemology, she risks talking past her opponent; her opponent might well be happy to grant that the distinction she identifies as the distinction between justified and unjustified belief is not

\footnotetext{
${ }^{11}$ See Brandt (1959) for a classic statement.

${ }^{12}$ See Goldman (1979).

${ }^{13}$ See, e.g., Joyce (1998), Pettigrew (2016).
} 
theoretically fundamental - perhaps it is somehow derived from the value of truth, as even many internalists accept. ${ }^{14}$ So if we want to maintain the prospect of a substantive dispute about whether subjects like Lara have justified or merely excused beliefs, we should look for some other theoretical role for the label "justified" besides that of marking whatever property of beliefs is most fundamental in epistemology.

My strategy in the rest of the paper will be to look to legal theory for some roles we might want justification, as distinct from excuse, to play. As a preview, classifying a defense as a justification rather than an excuse matters because there are further legal consequences, beyond mere immunity to punishment, that distinguish justifications from excuses. I'll provisionally assume a tight connection between justifying/excusing actions, and justifying/excusing beliefs: actions essentially based on justified (merely excused) beliefs are themselves justified (merely excused). This will allow me to neatly connect choice points in legal theory with choice points in epistemology, by allowing me to draw conclusions about the when beliefs are justified/excused, given premises about when actions are justified/excused. Later, I'll relax that assumption, and explore whether we might vindicate an epistemological distinction between justified and excused beliefs that is merely analogous to the legal distinction between justified and excused actionsthis will require looking for epistemological analogs of the downstream legal consequences that distinguish justification from excuses. While I won't attempt to stake out and defend a position on how best to distinguish epistemic justifications from epistemic excuses, I will argue that my discussion provides some reason for pessimism about knowledge first approaches to that project.

\footnotetext{
${ }^{14}$ See, e.g., BonJour (1985, Chapter 8).
} 


\section{Justifications and Excuses in the Law}

Before discussing how justifications and excuses differ, it's worth pausing to note some crucial features they have in common. The most obvious is that they both shield their bearers from retributive punishment. If my defense fully succeeds, then whether it's a justification or an excuse, I'm not going to jail. Perhaps less obviously, both justifications and excuses are "affirmative defenses". A defendant who offers a justification or an excuse responds to an accusation not with "no", but instead with "yes, but..." 15 This points to a potentially significant structural difference between both justifications and excuses in the law, and the notion of justification as it is used epistemology. Epistemologists are typically happy to ask of any belief some subject has, whether it is justified. Or even more broadly, of any proposition, believed or not, whether some subject has justification to believe that proposition. ${ }^{16}$ In the law, however, questions of justification and excuse only arise after it's been conceded that someone violated some prima facie norm. We can ask whether particular acts of theft or battery might be justified, excused, or neither, but to ask such questions concerning an everyday instance of sandwich consumption would be to commit a kind of category mistake.

What might an analogous conception of epistemic justification/excuse look like? Asking whether some belief was justified, merely excused, or neither would involve presupposing that it violated some prima facie norm. Perhaps questions of justification and excuse would only arise for beliefs that turned out to be false, or for beliefs in prima facie absurdities - "You think you were abducted by aliens? What's your justification for that?" 17 To conceive of epistemic justification along these lines would be quite different from present practice, and I won't try to explore the prospects for taking seriously the

\footnotetext{
${ }^{15}$ In this respect, justifications and excuses are more like defenses that appeal to statutes of limitations, and less like alibis.

${ }^{16}$ This distinction between doxastic and propositional justification was originally drawn by Firth (1978).

${ }^{17}$ So, far from factive conceptions of justification, we might end up with an anti-factive conceptionone on which only false beliefs can be justified.
} 
idea of justification as an affirmative defense - i.e., as a response to some conceded prima facie wrongdoing.

So much for their similarities - what about their differences? There are two main dimensions along which we might ask how justifications and excuses differ. First, we might ask how the conditions for having a justification differ from those for having an excuse. Second, we might ask how the consequences of having a justification differ from those of having an excuse. And of course, these questions will not be entirely independent - our views about what it takes to justify or excuse action should be sensitive to what commitments we take on in regarding an action as justified or excused.

My strategy in this section will be as follows. First, I'll give a few examples of paradigm justifications and paradigm excuses - i.e., paradigm types of justifying and excusing conditions. Then, I'll discuss a key disputed case, known as "reasonable mistake of fact." 18 While it is uncontroversially some type of affirmative defense, legal systems differ in whether they classify it together with paradigm justifications or paradigm excuses (and it is controversial among legal theorists how it should be classified). Here, I'll suggest that how we should classify it depends what role the justification/excuse distinction should play-how the consequences of having a justification should differ from those of having an excuse. I'll explore two common conceptions of this role-conceptions that are consistent in most cases, but which pull in opposite directions when it comes to reasonable mistake of fact. Relying on the provisional assumption that justified beliefs justify action, while merely excused beliefs will merely excuse action, I'll argue that depending on which conception of the role of the justification/excuse distinction we adopt, we can either vindicate a traditional epistemological internalist conception of justification, or a purely factive conception of justification on which justification requires only truth, but that neither of the main conceptions are congenial to the view that epistemic justification requires knowledge.

\footnotetext{
${ }^{18}$ The implied contrast intended by the qualifier of fact is typically of law-in most jurisdictions, under most circumstances, ignorance of the law is not treated as exculpatory.
} 


\subsection{Paradigm Justifications and Excuses}

While it's probably impossible to offer any uncontroversial general characterization of the distinction between justifications and excuses, a common initial gloss runs as follows: justifications pertain to the act, excuses to the actor. ${ }^{19}$ Justifying an act involves showing that, though it was of a type whose instances are typically wrong, given the totality of circumstances, it was the right thing to do after all. Excusing an act involves conceding that it was wrong, but arguing that, for some reason, the actor cannot be held responsible for it. Classic justifications include self-defense, necessity, and various species of authority. Normally, intentional homicide is a crime, as is destroying someone else's property, or breaking and entering. But if the reason I intentionally kill someone is because it's the only way to prevent that person from unlawfully killing me, then my act is justified by self-defense. If the reason I smash someone's car window is that doing so is the only way to save an infant in the car from heat stroke, then though I've damaged someone's property, my act is justified by necessity. And if the reason I break into and enter someone's home is that I'm a firefighter responding to an emergency call, my action is justified by authority. ${ }^{20}$

Classic excuses involve insanity, involuntary intoxication, and duress. Battery, vehicular manslaughter, and abetting robbery are typically punishable by prison sentences. But if the reason I hit you is that the voices in my head commanded me to, my act of battery may be excused. If the reason I crashed my car into yours is that I was involuntarily intoxicated - someone spiked my seltzer, perhaps - then my vehicular homicide may be excused. And if the reason I drove the getaway car for a bank robbery is that

\footnotetext{
${ }^{19}$ As Fletcher (1985) puts it, "Claims of justification concern the rightness, or at least the legal permissibility, of an act that nominally violates the law...Excuses speak not to the rightness or desirability of the act but to the personal culpability of the actor. (p. 954). Though even this much is controversial. Baron (2007) objects to this characterization of the distinction: "I do not think it generally important to draw a sharp distinction between appraisals of actions and appraisals of agents. It is an undercurrent of both this paper and some of my other work that it is often better to blur them, speaking in terms of the agent's conduct and thus about both action and character..." (emphasis in original).

${ }^{20}$ Other species of authority include law enforcement authority and parental authority, both of which can justify conduct that would otherwise be criminal.
} 
the person in the passenger seat had a gun to my head, I'll probably be excused.

The defenses I've been discussing so far are, by and large, uncontroversially classifiable either as justifications or as excuses. ${ }^{21}$ But the case I'll focus on, and which is of most relevance to epistemological debates - reasonable mistake of fact - is trickier. To imagine a situation in which a reasonable mistake of fact defense would be appropriate, start with a case in which a justification would be straightforwardly applicable. Now, modify the case so that, while the subject reasonably believes the situation to be one in which a justification is straightforwardly applicable, she is reasonably mistaken about the facts. This can be done with any justification.

For example, start with a case of self-defense or defense of others, but now modify the case so that, in fact, no genuine threat is present. Perhaps the would-be attacker is a method actor preparing for a role as a murderer. He is brandishing an unloaded gun, and has no intention of committing any actual violence. But the person who tackles him has no reason to suspect this. We could similarly modify the case of necessity so that it is just an extremely lifelike doll in the hot car, and so no destruction of property is actually necessary to preserve any infant's life. And we could modify the case of authority so that the address is reported incorrectly, and the house the firefighter breaks into was not the subject of any emergency call.

In each of these cases, we have a subject who performs some action that, were she better informed, would uncontroversially amount to an unjustified, inexcusable crime. But given that she's not better informed, and that her mistake is reasonable - cases of unreasonable mistake of fact are importantly different from the cases under present discussion $^{22}$ - should we classify her defense as a justification, or a mere excuse?

Before addressing this question, I want to say a bit about why I think it's potentially

\footnotetext{
${ }^{21}$ Duress is the trickiest case. While typically labeled an excuse, in at least some cases, it can look more like a justification. See Greenawalt (1986) for some helpful discussion.

${ }^{22}$ This isn't to say that unreasonable mistakes of fact are legally unimportant or interesting. Even an unreasonable mistake of fact can often serve as a (non-affirmative) defense by negating mens rea. See Dubber (2015, p. 83).
} 
of so much relevance to epistemologists. The notion of "reasonableness" in the common law tradition, while intentionally vague, flexible, and subject to jury interpretation, ${ }^{23}$ can look a lot like justification as conceived of by the internalist. It's not a factive notion; reasonable mistakes are possible. But it's also not completely subjective - not all sincerely held beliefs count as reasonable. In these respects, it resembles typical internalist conceptions of epistemic justification. Moreover, paradigm examples of the reasonable mistake of fact defense look like cases in which the beliefs the subject acts on are justified by internalist lights, but at best excused by the lights of the knowledge-first theorist. So the debate over how to classify the reasonable mistake of fact defense looks a lot like an action-focused analog of the debate between knowledge-firsters and their opponents surveyed in $\S 2$. And if we accept the pair of principles mentioned earlier in the paperthat actions essentially based on justified beliefs are themselves justified, while actions essentially based on merely excused beliefs are merely excused - then taking a position on whether actions based on reasonable mistakes - read: actions based on internalistically justified but nevertheless not knowledgable beliefs - are justified or merely excused will commit us to a position on whether the mistaken beliefs themselves are justified or merely excused.

So why is it that theorists - and legal systems - have been drawn in opposing directions when it comes to the reasonable mistake fact defense? In brief, in some respects it resembles paradigm excuses, while in others it resembles paradigm justifications. On the excuse side, cases of reasonable mistake of fact are cases in which somebody takes an act that, from a point of view of an omniscient observer, is regrettable. But on the justification side, actors who make reasonable mistakes of fact don't exhibit the sorts of diminished capacity that paradigmatically excused actors do.

It's uncontroversial that the actors in the cases I've imagined should not be subject to punishment. So if we're to make sense of the question of whether these defenses

\footnotetext{
${ }^{23}$ See, e.g., Fletcher (1985, p.953).
} 
should be classed as justifications or excuses, we need some further explanation of what role the classification plays, beyond shielding an actor from punishment. ${ }^{24}$ It's to some potential such explanations that I'll now turn.

\subsection{Downstream Consequences of Justifications and Excuses}

The two main proposed functional differences between justifications and excuses that I'll focus on are as follows. First, I'll discuss the idea that justifications should shield their bearers from a wider variety of negative consequences than excuses. Second, I'll discuss the idea that whether an actor is justified or merely excused has implications for third parties - whether they can be held liable as accomplices to the actor's conduct, whether they are permitted to aid or hinder that conduct, and the like. While these two ideas are consistent in their application to most defenses - we can uphold both of them while agreeing that, e.g., self-defense is a justification and insanity is an excuse-I'll argue that they pull us in different directions when it comes to classifying the reasonable mistake of fact defense; we're forced to choose between them, and depending on which we prioritize we'll classify the defense differently. While these aren't the only two ways legal theorists have proposed to functionally distinguish between justifications and excuses, the others are unlikely to have any upshots for the classification of reasonable mistake of fact defense, and so are unlikely to shed light on debates about justification and excuse in epistemology, so I relegate discussion of them to a footnote. ${ }^{25}$

\footnotetext{
${ }^{24}$ As Greenawalt (1986) puts it:

If the exclusive purpose of criminal law were to allocate an appropriate amount of punishment to those accused of doing wrong, the law would not need to distinguish between justifications and excuses. (p. 90)

${ }^{25}$ Other functional differences concern burdens of proof, and the retroactive applicability of changes in the classification of defenses (both of which are discussed in Dressler 2015, Chapter 17). With respect to the former, the general idea is that it ought to be harder for the state to shift the burden of proof to the defendant if the defendant is alleging that her conduct was justified, as opposed to merely excused.

With respect to the latter, the issue concerns cases in which an actor's conduct is covered by some defense at time $t_{1}$, but she is then tried at $t_{2}$ after which the law has changed such that her conduct would not be covered by the new version (if any) of the defense. The thought is that which regime she should be tried under depends on whether the defense was a justification or an excuse; if it was a
} 


\subsection{Non-Punitive Sanctions}

Perhaps the most direct way in which the justification/excuse distinction can be legally consequential is in determining just what happens to the accused when the trial is over. Morse (1998, p.334) puts it nicely:

...[T]he characterization of a defense as a justification or as an excuse may substantially alter the outcome: a justified defendant is properly and entirely freed as well as acquitted; an excused defendant who may continue to be a nonresponsible agent and a danger to society may be subject to civil or quasi-criminal interference with her liberty.

This distinction is easiest to see with excuses like insanity. A successful insanity defense against a criminal charge will typically not lead to the defendant's walking away free, and in many cases may lead to a longer period of incarceration - albeit of a different, putatively non-punitive sort - than would conviction in the absence of such a defense. (Elliott et al., 1993) By contrast, a justification for a criminal charge will shield its bearer both from prison, and from commitment to a psychiatric institution.

To take a less dramatic example, imagine someone is charged with vehicular homicidea crime punishable by an extensive prison sentence - and consider two ways she might defend herself. First, she might offer the excuse that she is epileptic, and had a seizure that led her to lose control of her vehicle, swerving into a pedestrian. Given the right background conditions - e.g., she didn't have prior knowledge of the condition, and had no reason to expect that she couldn't safely operate a motor vehicle - such an excuse

justification, then the actor was permitted to rely on it as a rule of conduct, and so can appeal to the law as it was at $t_{1}$ to justify her action; imagine a case in which a statute defining self-defense initially lacks a proportionality requirement, and one is later added. Under this theory, because self-defense is a justification, an actor who defends herself using force that would be disproportionate to the threat by the lights of the law as it stands at $t_{2}$, can nevertheless appeal to the law as of $t_{1}$ to justify her conduct. By contrast, if it was an excuse that was changed-perhaps a stricter definition of insanity was adopted - an actor would not be entitled to defend herself by arguing that she would have qualified for an excuse under the $t_{1}$ law. 
should save her from jail. But she'll probably still lose her driver's license. ${ }^{26}$

By contrast, if she can justify her act-suppose she uncovers CCTV footage showing that five children jumped into the road immediately in front of her vehicle, which lets her make the case that swerving into the one pedestrian was the only way to avoid killing the five - then not only will she avoid jail, but she'll keep her license too.

More generally, the idea is that justifications are principled barriers to (almost) any penalty, while excuses are barriers only to punishment. ${ }^{27}$ Insofar as preventive detention in a mental institution or the forfeiture of one's driver's license aren't understood as punishments, they aren't in principle off the table as consequences for a merely excused actor. Of course, that's not to say that whenever an actor is merely excused, she will or should suffer some non-punitive sanction; in many, perhaps most cases of excuse, no such sanctions are called for. Rather, it's to say that excuses don't provide principled barriers to such sanctions, while justifications do.

This proposal for how to functionally distinguish justifications from excuses-how their consequences differ-fits more neatly with some views about what it takes to have a justification (or an excuse) than others. In particular, it fits neatly with views on which showing that an actor conducted herself ideally — as well as could be expected of anyone in her circumstances - is enough to justify that act. By contrast, on such views, excusing an act will involve conceding that the actor's conduct was less than ideal, but nevertheless blameless. Marcia Baron (2007, p.399) puts the distinction as follows:

...to most of us, I think, it does indeed matter whether we are told, "We won't blame you; we understand that it would be too much to ask you to do better than you did"; or instead, "We won't blame you; for heaven's sake,

\footnotetext{
${ }^{26}$ See https://www.epilepsy.com/driving-laws for some information on how the relevant laws vary from state to state in the US.

${ }^{27}$ The "almost" is crucial. Famously, people who act with the justification of "private necessity" roughly, like regular necessity, but where the beneficiary of the necessary action is the actor-are still civilly liable for damages their justified actions cause. The classic case illustrating this principle is Vincent v. Lake Erie Transportation Co., decided by the Supreme court of Minnesota in 1910.
} 
you conducted yourself in a way that was exemplary."

As I interpret it, Baron's point is that excused actors manifest some defect — albeit a blameless one - while justified actors manifest no defect at all. This is why we generally prefer to be justified than excused. This idea fits neatly with the present proposal for functionally distinguishing justifications from excuses. If excused actors manifest a defect, then, depending on the nature of that defect, it may make sense for them to be treated differently from other actors who have no such defect-e.g., restricting their freedom of movement, or their driving privileges - even though it won't be appropriate to punish them (because the defect is not one for which they are to blame). And by the same token, because justified actors manifest no defect, there's no reason for them to suffer any loss of rights or privileges that they had prior to trial.

Supposing we prioritize this way of functionally distinguishing justifications from excuses, it's extremely natural to classify reasonable mistake of fact as a justification, rather than an excuse. In paradigm cases of the defense, the conduct of an actor reasonably mistaken about the facts manifests no defect, and a fortiori no defect that could justify non-punitive sanctions. In fact, in many cases, had the actor acted in the way that would've been best given the actual facts, rather than the facts as she reasonably believed them to be, she would have manifested a defect. Hamish Stewart (2003) discusses a case in which a law enforcement officer shoots a suspect, believing the suspect was about to shoot his partner. As it turns out, the suspect's gun was unloaded. Had the law enforcement officer known the gun was unloaded, he wouldn't have shot the suspect, since he could've been safely subdued with less force. But given his evidence, it would have been a dereliction of his duty to his partner not to shoot the suspect. ${ }^{28}$ Some kind of sanction - perhaps desk duty - would be appropriate in the case where the officer fails to shoot the suspect, but not in the case where he shoots the suspect on the

\footnotetext{
${ }^{28}$ Stewart's argument, in defense of classifying reasonable mistake of fact as a justification, strikes me as strongly reminiscent of the internalist epistemological arguments from Madison and Schechter quoted earlier in this essay.
} 
basis of a reasonably mistaken belief about whether the gun was a genuine threat.

Given the earlier assumption that justified beliefs justify actions, while merely excused beliefs will merely excuse actions, adopting this conception of the functional role of justification, along with the view that reasonable mistake of fact should be classified as a justification, will push us towards an epistemological view on which beliefs needn't be true in order to be justified.

Of course, there are difficult, intermediate cases - cases where someone acts on a mistaken belief that is neither obviously reasonable, nor obviously not. One can consistently adopt the conception of the functional role of the justification/excuse distinction I've been discussing in this section, while thinking that some mistake of fact defenses ought to be thought of as excuses, on the grounds that the mistaken belief on the basis of which the accused acts does manifest a defect, albeit a blameless one. Perhaps a case where a law enforcement officer shoots someone who's not even carrying a gun, but merely something that looks a bit like a gun, would be such a case; there we might think that ideal conduct wouldn't have led to a decision to shoot, but, depending on how easy a mistake it is to make, the officer might be excused for making it. But since he is merely excused, some kind of modification in his status might be appropriate; perhaps he should still be relegated to desk duty.

It will be difficult to decide, on a case by case basis, where to draw the boundaries between reasonable beliefs that justify actions, less than fully reasonable but nevertheless blameless beliefs that merely excuse them, partially blameworthy beliefs that mitigate wrongdoing, and wholly inexcusable beliefs that merely explain, without excusing or justifying, the actions based on them. But what's clear is that, given the present conception of the functional role of the justification/excuse distinction, the boundary between a justified belief and a merely excused one shouldn't depend on whether the belief is true. In some circumstances, an agent who is conducting her epistemic and practical affairs in ideal, exemplary fashion will nevertheless end up with a false belief. If she acts on 
that belief, she should have a principled shield against any sanctions - punitive or nonpunitive - because in doing so she has not manifested any defect, blameworthy or not, that the legal system can legitimately concern itself with. And if the crucial functional role of justification, as distinct from excuse, is that it provides such a shield, then we should regard such agents as acting justifiably. If we also we hold that actions essentially based on merely excused beliefs cannot be justified, then once we regard such agents as acting justifiably, we're committed to holding that the false but reasonable beliefs they act on are themselves not merely excused, but justified. That is, we must come down on the internalist side of the debate surveyed in $\S 2$.

\subsection{Justification and Third Parties}

Perhaps the most common proposal for what functionally distinguishes justifications from excuses concerns their differential consequences for third parties. If I'm justified in my action, then not only should I not be punished, but others shouldn't be punished for aiding or abetting me. By contrast, if I'm merely excused, then while I will escape punishment, my accomplices will not. As Chiesa (2014, p.330) summarizes, "justifications transfer to third parties, whereas excuses are personal to the actor."

Like the principle discussed in the previous section, this principle fits neatly with paradigm cases of justification and excuse. If I'm justifiably defending myself against an unjust aggressor, then not only should I escape punishment, but third parties shouldn't be punished for aiding me, nor should they hinder me in using force against my attacker. Along similar lines, if I'm trying and failing to break the window of car in which an infant is suffering heat stroke, third parties would do right in aiding me - perhaps by providing me with something heavy to use to break the glass. By contrast, if I'm suffering from a violent psychotic episode, while I may be excused for harm I cause, third parties shouldn't be punished for restraining me, and would be rightly subject to punishment if, instead, they provided me with firearms. They can't take advantage of my excuse. 
Similarly, if I've been involuntarily intoxicated, while I might have an excuse for harm I cause, a third party who understands the situation would have no excuse for handing me my car keys and wishing me a pleasant journey.

Unlike the principle in the previous section, the principle that justifications transfer to third parties most naturally fits with classifying reasonable mistake of fact as a mere excuse, rather than a justification. The reason is that if I, as a third party, understand that somebody is acting on the basis of a mistake, then even if she manifests no defecteven if her mistake really is fully reasonable - I shouldn't aid her, and should hinder her if I can. For example, if I know that it's just a highly lifelike doll in the car, then I shouldn't hand a hammer to the would-be hero trying to break the window. But if we regard that reasonably mistaken person as justified in breaking the window, and we hold that justifications transfer to third parties, then we get the absurd conclusion-absurd no matter where we draw the boundary between justification and excuse - that I would be justified in giving her a hammer. ${ }^{29}$

Suppose we want to vindicate in full generality the third party transfer principle. What view about justified belief - assuming that justified beliefs justify actionsnaturally follows? Another way to put it - what property must a belief have in order for actions based on that belief to be thereby justified? As we've just seen, it's clear that reasonableness won't suffice; reasonableness is compatible with mistake, and we don't want actions essentially based on mistakes to be aided. But it's just as easy to see that knowledge isn't required. As long as your belief that there's an infant in the car suffering heatstroke is true, then we want third parties to aid you in taking actions based on that belief, even if the belief doesn't amount to knowledge. In fact, as the example I'm about to discuss will bring out, vindicating the third-party transfer principle leads most naturally to a view where whether an act is justified doesn't really depend on the quality of

\footnotetext{
${ }^{29}$ Legal theorists who argue for classifying reasonable mistake of fact as a justification are aware of this problem, and will typically just deny that the third-party transfer principle holds in full generality. See, e.g., Baron (2007, p.404).
} 
the actor's beliefs at all, but only on the facts themselves. That is, so long as there exist facts sufficient to justify some action, then we hope third parties will aid and not hinder the actor, regardless of whether he himself acts on the basis of beliefs-knowledgeable or not-concerning these facts.

Paul Robinson (1998) describes a real-life case that nicely brings out this point:

Motti Ashkenazi, a thin, almost gaunt-looking man from a poor, crime-ridden South Tel Aviv neighborhood, is strolling along a crowded Jerusalem beach between Tel Aviv and Jaffa on a hot Friday afternoon in June 1997. A drug addict and petty thief who only a week ago had been arrested after bungling a car burglary, Ashkenazi has been thinking for a while about getting off drugs and putting his life together. But the going has been tough even with the support of his family.

As he walks, he sees that someone has left a black backpack unattended in an open area by the sidewalk. The 30-year-old Askhenazi looks around but sees no one watching. He picks up the backpack and quietly sneaks off, pleased by his good fortune. Without opening the backpack to inspect his loot, he walks down nearby Guela street to a rundown apartment building and slips inside. There in the stairwell, he unzips the backpack. Inside he sees a clock with wires connected to a cookie tin, with loose nails surrounding the contraption. Ashkenazi quickly realizes he just stole a bomb. (p. 388)

Motti committed theft— - he took someone else's property without permission. Moreover, his conduct was far from laudable. Even so, we should want third parties with an accurate view of the situation to aid people in his situation. If somebody were to see that Motti was having a hard time carrying the bag away from the crowded beach, we'd want the law to encourage giving him a hand. Even if he doesn't know it - doesn't even believe it - if the third-party transfer principle is our guide, then Motti's thievery must 
be ruled justified, as he should be helped rather than hindered.

That is, vindicating the third-party transfer principle will push us towards what is sometimes called an "objectivist" or "deeds"-based approach to justification, on which whether an act is justified depends not on the mental state of the actor, but on the objective facts of the situation. ${ }^{30}$ So strictly speaking it's probably best to interpret such a view as severing any interesting connection between the justification of belief, and the justification of action; even with an "objectivist" view of epistemic justification, on which it just amounts to truth, the view under consideration does not entail that justified actions must be based on justified beliefs. After all, Motti's action was crucially based on the false belief that the bag he was carrying didn't contain a bomb. But if we must extract a view about justified belief from this view about the justification of action, then the view that justification just amounts to truth is the natural candidate.

While not necessary, being based on true beliefs is a kind of minimal sufficient condition for an action to be justified, given the view under consideration. ${ }^{31}$ That is, we can distinguish views about what's required for justification by their answer to the following question. If you're acting in the way that, were your beliefs true, then your action would be for the best, what feature of your beliefs would guarantee that your action is justified? The view about justification we saw in the previous section would answer: reasonableness. (Where, again, the notion of reasonableness at issue is non-factive; it allows for reasonable mistakes.) If your beliefs are reasonable, and you're acting such that, if your beliefs were true then your action would be for the best, then your action is justified. The knowledge-first view says: knowledge. That is, even if you're doing what is best in light of the actual facts, if you're acting on the basis of beliefs that don't amount to knowledge, then your action isn't justified. The view motivated by the third-party

\footnotetext{
${ }^{30}$ This is the view Robinson (1998), who describes the case, favors. It is also the view enshrined in Israeli law; Motti walked free.

${ }^{31}$ This isn't quite right, since clear-eyed wrongdoing is possible-actors can do wrong on the basis of true beliefs. So the "based on" in the sentence in the text should really be interpreted as "properly based on", in the sense that an action is properly based on some beliefs just in case, were the beliefs true, the action really would be for the best.
} 
transfer principle imposes weaker requirements than the knowledge-first view. If you're doing what would be best if your beliefs were true, and your beliefs are true, then we want the law to encourage third parties to aid you, and not to hinder you - after all, your action is for the best. So prioritizing the third-party transfer principle gives us the result that being based on true beliefs is sufficient for an action to be justified.

\subsection{A Hybrid View?}

Some legal theorists defend views about justification that can look more congenial to the knowledge-first picture. Gardner (1996), for instance, argues that for an action to be justified, there must be a match between the actual reasons in favor of an action, and the considerations that motivated the actor to perform it. ${ }^{32}$ This looks like a view on which justified actions must not only be best in light of the facts - as the third party transfer principle would have it - but where there's still some kind of requirement on the mental state of the actor claiming the justification. A view like Gardner's is easily able to rule agents like Motti as unjustified-while there were excellent reasons for him to steal the backpack, they had nothing to do with the considerations that actually motivated him.

Gardner himself doesn't say enough about just what it takes for there to be a match between the actual reasons and one's motivations to make it clear whether he himself would favor the view that justified actions must be based on knowledge. ${ }^{33}$ But regardless of his own view on the matter, we can ask whether such a view might be motivated,

\footnotetext{
${ }^{32}$ In his terminology: "No action or belief is justified unless it is true both that there was an applicable (guiding) reason for so acting and that this corresponded with the (explanatory) reason why the action was performed or the belief held."

${ }^{33} \mathrm{~A}$ reason for skepticism: he presupposes that justified beliefs can be false. In describing excused actors, he writes the following:

The point must be that there is something suspect about the reasons for which they act. And indeed there is. They are not valid reasons. They are what the person acting upon them takes to be valid reasons, and justifiably so. Thus the structure of excuse derives from the structure of justification. To excuse an action is not, of course, to justify that action. Rather, one justifies one's belief that the action is justified. (1996, p. 119, emphasis in original)

Of course, this position is inconsistent with the view that justified belief is knowledge, since it presupposes that an agent can have a justified belief that her action is justified, when in fact it is merely excused.
} 
given the kinds of broadly functionalist reasons for caring about the justification/excuse distinction.

It's far from crazy to think the legal system should treat actors like Motti differently from paradigmatically justified actors. Given the sorts of broadly future-looking considerations emphasized in $\S 3.3$, it's natural to think that Motti should be treated no differently from any other thief; nothing about his conduct suggests that he's any less likely to steal again than a run-of-the-mill thief.

But is there room for respecting that motivation for treating Motti as unjustifiedand also unexcused - without collapsing back into the view discussed in $\S 3.3$, on which reasonable mistake of fact is a justification? We might hold the following kind of hybrid functional view. Justified actors should both be shielded from punitive and non-punitive sanction, and should be aided and not hindered by third parties. So rather than prioritizing either of these apparently conflicting ideas, we flat out accept both positive theses, while rejecting the negative ones. That is, if we accept this hybrid view, we won't be able to say that only justified actors should be shielded from punitive and non-punitive sanctions (remember the reasonably mistaken), or that only justified actors should be aided by third parties (remember Motti).

Whatever the merits of this view, it doesn't mesh nicely with the position that justified action must be based on knowledge. To see why, imagine a fictional variant of Motti's case. In this version, Motti is an ammunition technical officer (ATO), responding to a bomb threat. As it turns out, the threat was a hoax - it was called in by a student who was hoping to get his math test canceled. But the description given in the hoax call happens to match a genuine bomb-containing backpack, which Motti finds. As Motti moves the backpack, he doesn't know it contains a bomb. He believes it contains a bomb, and that belief is true, but it's just dumb luck; Motti is in a Gettier case.

Nevertheless, it's hard to see what reason the law could have for caring that Motti's "theft" isn't based on knowledge of justifying conditions. As in the true version of the 
case, his conduct is of a sort that we hope third parties would aid, rather than hinder. So if we prioritize the third-party transfer principle we'll say he's justified. Unlike in the true version of the case, in the fictionalized version his conduct is laudable - we shouldn't want ATO Motti to suffer any sanctions of any sort for his behavior. So if we nevertheless hold that his action is unjustified — we'll presumably say it is excused — we're left unable to appeal to any of the standard explanations of why it matters whether we classify defenses as justifications or excuses.

Stepping back, my strategy so far has been to look at two functional roles for the justification/excuse distinction to play, and how prioritizing one or the other role will motivate drawing the boundaries of justification and excuse differently in the key cases of interest to epistemologists - cases of reasonable but false beliefs. Without taking a stand on which, if either, we should prioritize - for all I've said here, we might want to be pluralists, and/or to distinguish different species of "justification", one of which shields its bearer from non-punitive sanctions, and the other of which has implications for the propriety of third party aid and hindrance-I've argued that neither provides resources congenial to the knowledge-based view of justification. While there are reasons in legal theory to distinguish between beliefs that are reasonable and beliefs that are unreasonable, and other reasons to distinguish between beliefs that are true and beliefs that are false, at least when it comes to justification and excuse, we haven't seen legal reasons to care about the distinction between beliefs that amount to knowledge, and those that don't.

In the next section, I'll relax the guiding assumption I've been relying on, according to which there is a tight connection between justifying belief and justifying action. I'll explore the prospects for vindicating a justification/excuse distinction for belief that is merely analogous to the distinction between justified and merely excused action. 


\section{Epistemic Justification as Merely Analogous to Legal Justification}

In the previous section, we saw that debates over how to classify defenses as justifications or excuses in legal theory are substantive insofar as there are further downstream consequences - beyond immunity to punishment - that distinguish justifications from excuses. If we want to vindicate as substantive debates over whether beliefs are epistemically justified or merely excused, one strategy we can pursue is to directly piggyback on the legal theoretic strategy - assume that whether someone has a legal justification or excuse somehow depends on whether they have an epistemic justification or excuse, so that debates about how to distinguish epistemic justifications from excuses are automatically substantive if the analogous legal debates are. That's the strategy I've been pursuing so far. The strategy I'll explore in this section is less direct. Rather than piggybacking on the significance of the legal distinction, I'll ask whether we can find, internal to epistemology, something analogous to the downstream legal consequences that distinguish justifications from excuses. That is, insofar as we agree that both epistemic justifications and epistemic excuses shield their bearers from (some species of) blame, I'll look for downstream epistemological consequences that might distinguish them, so that we'd have a vindication of the substantiveness of the epistemic justification/excuse distinction that was parallel to, rather than derivative of, the substantiveness of the analogous legal distinction.

While there's a rich tradition of thinking of ethical norms as distinctive in that their violation warrants blame, resentment, or guilt, ${ }^{34}$ and legal norms as distinctive in that their violations warrant various varieties of legal sanction, the idea of epistemic norms as distinguished by the sorts of reactions that their violations warrant is much less common. ${ }^{35}$ This makes our current task harder. We'd like to have a rich array

\footnotetext{
${ }^{34}$ See, e.g., Gibbard (1990) and Darwall (2006).

${ }^{35}$ Though see Kauppinen (Forthcoming).
} 
of potential reactive attitudes to violations of epistemic norms to choose from, so that we might distinguish epistemic justifications from epistemic excuses by looking to which further reactions they block, while being similar in shielding their bearers from blame. But that way of framing the problem is already loaded; the idea that justifications and excuses are similar in shielding their bearers from blame seems to presuppose that, normally, cases of norm-violation warrant blame as a reaction. In law and morality, this is plausible, but in epistemology, it's not obvious. The idea that violations of epistemic norms are even prima facie blameworthy — where that default blameworthiness might be defeated by the presence of a justification or an excuse - is controversial. ${ }^{36}$

However, there is one strand in the recent epistemological literature that may prove helpful. A number of epistemologists have thought that an important part of the function of epistemological concepts is that they help us identify reliable informants, (Craig, 1990). The idea, roughly, is that somebody who knows whether $\mathrm{P}$ - or even someone who merely has a justified belief as to whether P, provided they have no less evidence than you do - is somebody who you can treat as an "epistemic surrogate" (Dogramaci, 2012); she is someone whose belief on the matter you can responsibly adopt as your own. ${ }^{37}$ This sort of picture naturally pairs with the idea that violations of epistemic norms will defeasibly warrant withdrawals of trust or deference - when somebody forms an unjustified belief, we should be less willing to treat them as an epistemic surrogate. ${ }^{38}$

Once we adopt this picture, we have the resources necessary to draw a justification/excuse distinction in epistemology that parallels (one version of) the justification/excuse distinction in legal theory. We can think of the withdrawal of deference as analogous to the various non-punitive sanctions that are sometimes warranted in re-

${ }^{37}$ At least in the case of justification, this is controversial, as it probably depends on the assumption of "uniqueness": that a given body of evidence justifies a unique attitude towards any given proposition. See Greco and Hedden (2016) and Dogramaci and Horowitz (2016) on the connection between uniqueness on the one hand, and epistemic surrogacy on the other.

${ }^{38}$ Kauppinen (Forthcoming) defends a picture on which this is what identifies epistemic norms as epistemic; their violation warrants withdrawal of deference.
} 
sponse to merely excusable criminal actions. Just as insane actors won't be jailed, but may be institutionalized, merely excused believers won't be blamed, but we may rightfully treat them as less credible going forward. Suppose I learn that my aging mother was taken in by an email scam - she sent a great deal of money to someone claiming to be a Nigerian prince who needed assistance transferring funds out of the country, and who promised to pay her back a hundredfold. Given the right background conditionssenility, mainly - I probably won't blame her for her belief that she was sending money to a genuine prince. ${ }^{39}$ But, knowing that she made a mistake like this, I will take her judgment less seriously going forward - when she says she's found a promising investment opportunity, I'll be less inclined to trust, and more inclined to verify. By contrast, if she really were justified in believing she were dealing with a prince - it's hard to imagine the case, but fill in the details however you need to - then not only will I not blame her, but I won’t take her judgment any less seriously going forward.

If this is how we understand the distinction between justification and excuse in epistemology, then, we'll end up vindicating the internalist response to the knowledge-first position. Sometimes, beliefs that don't amount to knowledge are nevertheless exactly what you'd want a good epistemic surrogate to believe. To take the example from the very beginning of the paper, when I learn that Lara thought she was looking at a lemon, not only do I not blame her for this belief, but moreover I am no less inclined to trust her judgment going forward, nor should I be. On the present proposal, that's the mark of epistemic justification, rather than mere excuse.

Perhaps it's unsurprising that when we look for epistemic analogs of non-punitive sanctions, and treat the justification/excuse distinction as significant because of its consequences for whether those sanctions are warranted, we end up with a position that parallels the view in legal theory that focuses on non-punitive sanctions, and which clas-

\footnotetext{
${ }^{39}$ That's not to say that we would never blame somebody for such a belief. If I were to learn that my spouse, who has no recourse to senility-based excuses, sent money from our joint account to an email scammer, believing he was a prince, I would be justifiably angry.
} 
sifies reasonable mistake of fact as a justification. Can we find epistemic analogs of third party aid/hindrance, such that an epistemic justification/excuse distinction focused on consequences for the propriety of such aid/hindrance might support a factive, perhaps knowledge-based conception of epistemic justification?

It's far from clear what that might look like. In the case of action, aid and hindrance are easy enough to understand-I aid you when I help you accomplish your aim, and I hinder you when I make it more difficult for you to do so. What would it be for me to aid or hinder you in your belief, such that we might then understand justifications as differing from excuses in terms of their consequences concerning when third parties can aid or hinder you in your beliefs? While it's a bit of a stretch, one way we might interpret "hindrance" as applied to belief involves persuasion; I could "hinder" you in some belief of yours by trying to disabuse you of it. And I can "aid" you in a belief of yours merely in not trying to disabuse you of it. If this is how we think of aid and hindrance, and we hold that justified beliefs are ones that third parties should aid/shouldn't hindered, then I suggest we'll end up with a position analogous to the position discussed in $\S 3.4$, on which truth is necessary and sufficient for a belief to be justified. That is, suppose I am a third party who knows that you have a reasonable but mistaken belief. Perhaps you're Lara, and I'm someone who already tried to take a bite of the wax lemon, and so who knows it's a fake. Here, the fact that your belief is reasonable shouldn't prevent me from trying to disabuse you of it - from trying to save you from my waxy fate. So this framing will lead us towards thinking of reasonable but false beliefs as merely excused.

But, for similar reasons to the ones we saw in $\S 3.4$, it won't get us all the way to requiring knowledge for justification. Suppose you believe, but do not know, that one of the pieces of fruit in the bowl is wax. Maybe you're inclined towards paranoia, and tend to suspect that all food you're offered is somehow tainted. While it would be fine for me to try to disabuse you of that general belief, it would be perverse for me to try to convince you to give up the specific application to the case of the fruit in front of you. 
Rather, the more appropriate response would involve conceding that you happened to get things right this time - the lemon really is wax-while insisting that it really was just luck, and that this wasn't something you should have expected ex ante. That is, if we look for epistemological analogs of aid/hindrance, and hold that justified beliefs should be aided while merely excused beliefs shouldn't, then the natural thing to say seems to be that we should aid true beliefs and hinder false ones, without regards to whether they are reasonably or knowledgeably held.

\section{Conclusions}

My aim in this paper was to explore prospects for breaking an apparent deadlock. Internalists say that reasonable false beliefs are justified, knowledge firsters say they are merely excused. But there's enough background agreement-e.g., on the fact that false beliefs are somehow defective, and that reasonable false beliefs are somehow better than delusional beliefs - that it's not entirely clear just what turns on whether reasonable false beliefs should get the honorific "justified" or not. Following the methodological lesson of Chalmers (2011), my strategy was to look for some of the theoretical roles that we might care to pick out with "justification" and "excuse," and to then ask what sorts of properties of beliefs might be apt to play those roles. In the legal literature on justifications and excuses, I found one pair of roles for which the internalist conception of justification fits the bill - the role of shielding someone from both punitive and non-punitive sanctions, as contrasted with the role of shielding someone merely from punitive sanctions. I also found a pair of roles for which a truth-based conception of justification fits the bill - the role of both shielding someone from punishment and shielding third-parties who aid her from punishment, versus the role of doing only the former. But I found no roles for "justification" and "excuse" that mesh with the view that justification just is knowledge. 


\section{Justifications and Excuses in Epistemology}

A narrow conclusion we can draw is that the legal theoretic literature on justifications and excuses provides little aid and comfort to the knowledge-firster, and is more congenial to both the traditional internalist and the proponent of the less common view that justified beliefs are just true beliefs. But I think a broader conclusion can be drawn as well. In "A Plea for Excuses", Austin (1956) appeals to a kind of conceptual conservatism in defense of ordinary language philosophy:

Our common stock of words embodies all the distinctions men have found worth drawing, and the connexions they have found worth marking, in the lifetimes of many generations: these surely are likely to be more numerous, more sound, since they have stood up to the long test of the survival of the fittest, and more subtle, at least in all ordinary and reasonably practical matters, than any that you or I are likely to think up in our armchairs of an afternoon - the most favoured alternative method.

This sort of argument is often offered in favor of knowledge-first epistemology. ${ }^{40}$ "Knows" is a piece of ordinary language in a way that "reasonably believes", "believes with high probability", and "truly believes" are not. ${ }^{41}$ However, it's possible to offer a defense of the categories used in the common law that parallels Austin's defense of ordinary language. They embody all the distinctions judges and lawyers have found worth drawing and the connections they've found worth making across a body of case law that spans generations. And if the general thrust of this paper has been correct, then it's telling that —at least when it comes to justifying and excusing actions - while jurists have found reason to mark the distinction between reasonable belief and unreasonable belief, as well as the distinction between truth and falsity, the distinction between knowledge and ignorance has had no crucial role to play. The idea that some assortment of replacement concepts can do the work of knowledge, when proposed by a philosopher

\footnotetext{
${ }^{40}$ See, e.g., Stanley (2005, p. vi-vii).

${ }^{41}$ See, e.g., Nagel (2014, p.6).
} 
on the basis of an afternoon's thought, is apt to be less than persuasive. But when the proposal is based on the fact that these replacement concepts are already doing that work in our courtrooms, and have been for generations, then it should carry a good deal more weight. So in addition to my narrow conclusion, my broader aim in this paper has been to put a dent in the conceptual conservatism based case for knowledge-first epistemology.

\section{Bibliography}

Aarnio, Maria Lasonen. 2010. "Unreasonable Knowledge." Philosophical Perspectives 24:1-21.

Allen, Michael, 2015. Textbook on Criminal Law. Oxford University Press.

Alston, William, 2005. Beyond "Justification": Dimensions of Epistemic Evaluation. Cornell University Press.

Alston, William P. 1993. "Epistemic Desiderata." Philosophy and Phenomenological Research 53:527-551.

Austin, John Langshaw. 1956. "A Plea for Excuses." Proceedings of the Aristotelian Society 57:1-30.

Ballantyne, Nathan. 2016. "Verbal Disagreement and Philosophical Skepticism." Australasian Journal of Philosophy .

Baron, Marcia. 2007. "Justifications and Excuses." Criminal Law and Philosophy .

BonJour, Laurence, 1985. The Structure of Empirical Knowledge. Cambridge, MA: Harvard University Press.

Boult, Cameron. 2017. "Epistemic Normativity and the Justification-Excuse Distinction." Synthese 194:4065-4081. 
Brandt, Richard, 1959. Ethical Theory. Prentice Hall.

Chalmers, David. 2011. "Verbal Disputes." The Philosophical Review 120:515-566.

Chiesa, Luis, 2014. "United States of America." In "General Defenses in Criminal Law: Domestic and Comparative Perspectives," Ashgate.

Cohen, Stewart. 1984. "Justification and Truth." Philosophical Studies 46:279-95.

—. 2016. "Theorizing About the Epistemic." Inquiry : An Interdisciplinary Journal of Philosophy 59:839-857.

Craig, Edward, 1990. Knowledge and the State of Nature: An Essay in Conceptual Synthesis. Oxford: Clarendon Press.

Darwall, Stephen, 2006. The Second-Person Standpoint: Morality, Respect, and Accountability. Harvard University Press.

DeRose, Keith. 2002. "Assertion, Knowledge, and Context." Philosophical Review 111:167-203.

Dogramaci, Sinan. 2012. "Reverse Engineering Epistemic Evaluations." Philosophy and Phenomenological Research 84:513-530.

Dogramaci, Sinan, and Sophie Horowitz. 2016. "An Argument for Uniqueness About Evidential Support." Philosophical Issues 26.

Dressler, Joshua, 2015. Understanding Criminal Law. Carolina Academic Press.

Dubber, Markus D., 2015. An Introduction to the Model Penal Code. Oxford University Press.

Elliott, R.L., E. Nelson, W.L. Fitch, R. Scott, G. Wolber, and R. Singh. 1993. "Informed Decision Making in Persons Acquitted Not Guilty by Reason of Insanity." Bulletin of the American Academy of Psychiatry and the Law . 
Feldman, Richard. 2008. "Modest Deontologism in Epistemology." Synthese 161.

Firth, Roderick, 1978. "Are Epistemic Concepts Reducible to Ethical Concepts?" In Goldman, Alvin, and Jaegwon Kim, editors, "Values and Morals," D. Reidel Publishing Co.

Fletcher, George. 1985. "The Right and the Reasonable." Harvard Law Review .

Gardner, John, 1996. "Justifications and Reasons." In "Harm and Culpability," Oxford University Press.

Gerken, Mikkel. 2011. "Warrant and Action." Synthese 178:529-547.

Gibbard, Allan, 1990. Wise Choices, Apt Feelings. Cambridge Massachussetts: Harvard University Press.

Goldman, Alvin, 1979. "What is Justified Belief?" In Pappas, George S., editor, "Justification and Knowledge," Reidel.

Greco, Daniel. 2015. "Verbal Debates in Epistemology." American Philosophical Quarterly 51:41-55.

Greco, Daniel, and Brian Hedden. 2016. "Uniqueness and Metaepistemoloy." Journal of Philosophy 113.

Greenawalt, Kent. 1986. "Distinguishing Justifications from Excuses." Law and Contemporary Problems .

Hawthorne, John, and Jason Stanley. 2008. "Knowledge and Action." Journal of Philosophy 105:571-90.

Joyce, James M. 1998. "A Nonpragmatic Vindication of Probabilism." Philosophy of Science 65:575-603. 
Kauppinen, Antti. Forthcoming. "Epistemic Norms and Epistemic Accountability." Philosophers' Imprint .

Littlejohn, Clayton, Forthcoming. "A Plea for Epistemic Excuses." In Dorsch, Fabian, and Julien Dutant, editors, "The New Evil Demon," Oxford University Press.

Madison, B. J. C. Forthcoming. "On Justifications and Excuses." Synthese pages 1-12. Morse, Stephen. 1998. "Excusing and the New Excuse Defenses." Crime and Justice .

Nagel, Jennifer, 2014. Knowledge: A Very Short Introduction. Oxford University Press.

Pettigrew, Richard, 2016. Accuracy and the Laws of Credence. Oxford University Press.

Pryor, James. 2001. "Highlights of Recent Epistemology." British Journal for the Philosophy of Science 52:95-124.

Robinson, Paul. 1998. "The Bomb Thief and the Theory of Justification Defenses." Criminal Law Forum: An International Journal .

Robinson, Paul, and Michael Cahill, 2012. Criminal Law. Wolters Kluwer Law \& Business.

Schechter, Joshua, Forthcoming. "No Need for Excuses: Against Knowledge-First Epistemology and the Knowledge Norm of Assertion." In Carter, J. Adam, Emma Gordon, and Benjamin Jarvis, editors, "Knowledge-First: Approaches in Epistemology and Mind," Oxford University Press.

Srinivasan, Amia. 2015. "Normativity Without Cartesian Privilege." Philosophical Issues .

Stanley, Jason, 2005. Knowledge and Practical Interests. Oxford University Press.

Stewart, Hamish. 2003. "The Role of ReasReasonable in Self-Defense." Canadian Journal of Law and Jurisprudence . 
Justifications and Excuses in Epistemology

Sutton, Jonathan, 2007. Without Justification. MIT Press.

Williamson, Timothy, Forthcoming. "Justification, Excuses, and Sceptical Scenarios." In Dorsch, Fabian, and Julian Dutant, editors, "The New Evil Demon," Oxford University Press. 